\title{
Diabetes Technology: Monitoring, Analytics, and Optimal Control
}

\author{
Boris Kovatchev \\ Center for Diabetes Technology, University of Virginia, Charlottesville, Virginia 22908 \\ Correspondence: boris@virginia.edu
}

Over the past 50 years, the diabetes technology field progressed remarkably through selfmonitoring of blood glucose (SMBG), continuous subcutaneous insulin infusion (CSII), risk and variability analysis, mathematical models and computer simulation of the human metabolic system, real-time continuous glucose monitoring (CGM), and control algorithms driving closed-loop control systems known as the "artificial pancreas" (AP). This review follows these developments, beginning with an overview of the functioning of the human metabolic system in health and in diabetes and of its detailed quantitative network modeling. The review continues with a brief account of the first AP studies that used intravenous glucose monitoring and insulin infusion, and with notes about CSII and CGM-the technologies that made possible the development of contemporary AP systems. In conclusion, engineering lessons learned from AP research, and the clinical need for AP systems to prove their safety and efficacy in large-scale clinical trials, are outlined.

In health, glucose metabolism is tightly controlled by a hormonal network, including the gut, the liver, the pancreas, and the brain to ensure stable fasting blood glucose (BG) levels and transient postprandial glucose fluctuations. In diabetes, this network control is disrupted by deficiency or absence of insulin secretion, which needs to be compensated for by technological means and/or behavioral changes (e.g., exercise, diet). Generally, diabetes is classified into type 1 and the much more prevalent type 2 diabetes, accounting for $90 \%-95 \%$ of all cases. Type 1 diabetes is characterized by absolute deficiency of insulin secretion resulting from autoimmune response targeting the $\beta$ cells in the islets of Langerhans of the pancreas - the site of insulin secretion and synthesis. In general, the disease occurs in childhood and adolescence (although it can occur at any age) and was also known in the past as "insulin-dependent diabetes mellitus" (IDDM) or "juvenile diabetes." Affected individuals require insulin to control hyperglycemia and sustain life (Pickup and Williams 2003; American Diabetes Association 2004; Wilson et al. 2011). Type 2 diabetes is triggered by a combination of impaired insulin action and insufficient $\beta$-cell function and occurs because insulin secretion is inadequate and cannot overcome the prevailing defects in insulin action, thereby resulting in hyperglycemia (elevated BG levels). Excess caloric intake, inactivity, and obesity all play parts in the pathogenesis of type 2 diabetes. In general, it is a disease that occurs with increasing frequency in increas-

Editors: Valentin A. Pavlov and Kevin J. Tracey

Additional Perspectives on Bioelectronic Medicine available at www.perspectivesinmedicine.org

Copyright (C) 2019 Cold Spring Harbor Laboratory Press; all rights reserved; doi: 10.1101/cshperspect.a034389

Cite this article as Cold Spring Harb Perspect Med 2019;9:a034389 
ing age. People with type 2 diabetes are also more likely to have associated adverse cardiovascular risk factors such as dyslipidemia and hypertension. Pre-diabetes, that is, impaired fasting glucose (IFG) and impaired glucose tolerance (IGT), is an intermediate condition in the transition between normal metabolism and diabetes. People with IGT or IFG are at high risk of progressing to type 2 diabetes, although this is not inevitable. Both type 2 diabetes and pre-diabetes are recognized risk factors for overt cardiovascular disease and related metabolic complications (Pickup and Williams 2003; American Diabetes Association 2004; Wilson et al. 2011). Overall, diabetes is a complex of metabolic disorders characterized by chronic hyperglycemia that could lead to microvascular and macrovascular complications, which in turn could trigger limb loss, blindness, heart disease, and renal disease. There is no cure; the only proven treatment for both type 1 and type 2 diabetes is the tight control of BG fluctuations (The Diabetes Control and Complications Trial Research Group 1993, 1995; Reichard and Pihl 1994; UK Prospective Diabetes Study Group 1998; Lachin et al. 2008).

Thus, people with diabetes face a lifelong optimization problem: to maintain strict glycemic control without increasing their risk for hypoglycemia. In clinical terms, the optimization problem of diabetes was formulated as a "tradeoff between glycemic control and iatrogenic hypoglycemia" (Cryer 2014), meaning that lowering of hemoglobin A1c-the primary marker of average glycemic control-must be accompanied by concurrent mitigation of the risk for hypoglycemia. This postulate, however, is strictly focused on desired glycemic outcomes and does not prescribe means for achieving optimal control. Given that undesirable glycemic variation is triggered at multiple biosystem levels and is driven by self-treatment behavior, the key to optimal diabetes treatment is a multilayer holistic approach, which uses advanced technology when appropriate/accepted by the patient, and accounts for individual factors of human behavior. This is well understood, and the external regulation of diabetes is now an interdisciplinary endeavor with significant bioengineering component.
To put the progress of bioelectronic medicine for diabetes in perspective, for the 2000 years following the clinical introduction of the term diabetes (Aretaeus the Cappadocian, first century $\mathrm{AD}$ ), diet was the only treatment (albeit unsuccessful in type 1 diabetes). In the 19th century, the nature of diabetes was generally understood, and, with the discovery of insulin in 1921 by Frederick Banting at the University of Toronto, type 1 diabetes was no longer a death sentence. For this breakthrough, Banting and John Macleod were awarded the Nobel Prize in Physiology or Medicine in 1923. To recognize the contributions of their colleagues, Banting shared his prize with Charles Best and Macleod shared his with J.B. Collip. Insulin injections became the standard treatment for type 1 diabetes and for many people with type 2 diabetes. The field of diabetes medicine was born.

On March 6, 2013, the American Diabetes Association (ADA) published research showing that the total costs of diagnosed diabetes in the United States have risen to $\$ 245$ billion in 2012 from $\$ 174$ billion in 2007, a $41 \%$ increase over 5 years (American Diabetes Association 2013). Therefore, diabetes is a prime example of an enormous health care problem, the only solution of which is integration of behavioral change, advanced technologies aiming at functional replacement of the failing $\beta$ cell, and synergistic drug-device integration. Given that diabetes is common and affects millions of people around the world, major efforts targeting the optimization of diabetes control and large international organizations are dedicated to the treatment and, ultimately, the cure of diabetes and its complications, including the ADA, the European Association for the Study of Diabetes (EASD), the International Diabetes Federation (IDF), and the Diabetes Technology Society. These efforts are picking up speed and new diabetes treatments relying on bioelectronics advancements are being introduced daily.

\section{THE HUMAN GLUCOSE-INSULIN CONTROL NETWORK}

As presented in Figure 1A, BG levels are raised by food containing carbohydrates, and glucose 

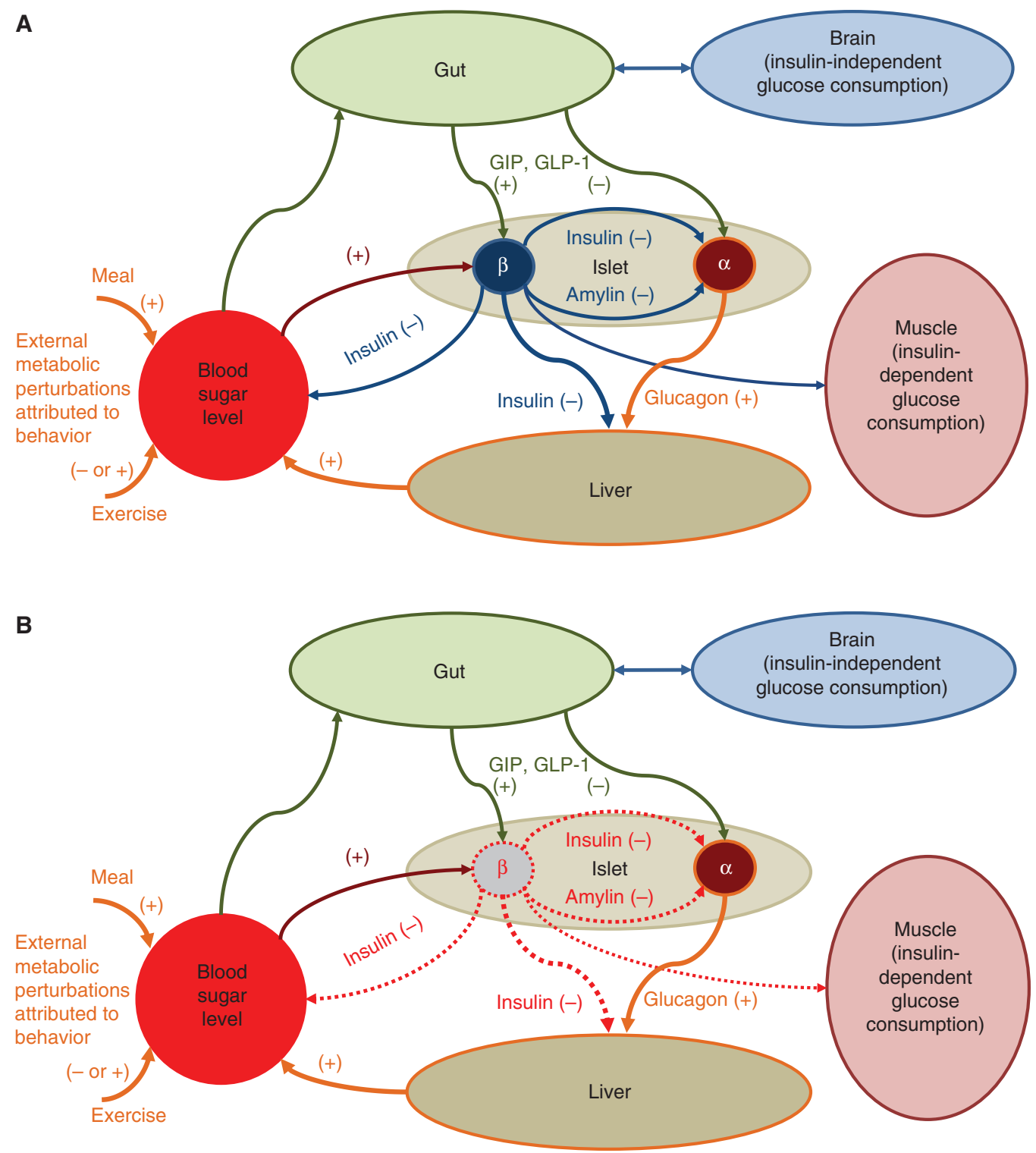

Figure 1. The glucose-insulin control network. Network in health $(A)$ and type 1 diabetes $(B)$. The pathways marked with (+) exert positive influence on blood glucose (BG) levels; the pathways marked with (-) lower BG. In type 1 diabetes, all insulin-dependent glucose-lowering pathways are nonfunctional because of a lack of endogenous insulin secretion. Thus, exogenous insulin replacement is mandatory.

is also produced by the body (mainly by the liver), after which it is distributed and utilized through both insulin-independent (e.g., central nervous system and red blood cells) and insulindependent (muscle and adipose tissues) pathways. Insulin secreted by the pancreatic $\beta$ cell is the primary regulator of glucose homeostasis; it reaches the system circulation after liver degradation and is peripherally cleared primarily by the liver. The glucose and insulin systems interact by feedback control signals. If a glucose perturbation occurs (e.g., after a meal), $\beta$ cells secrete more insulin in direct response to increased plasma glucose concentration, or as 
indirect response to hormonal release from the gut, GIP and GLP-1, known as the "incretin effect” (Nauck et al. 1986a). In turn, insulin signaling promotes glucose utilization and inhibits glucose production to bring rapidly and effectively plasma glucose to its preperturbation level. These control interactions are usually referred to as insulin sensitivity and $\beta$-cell responsivity (Cobelli et al. 2009). In pathophysiology, this feedback control is degraded. In type 2 diabetes, the network in Figure 1A is largely preserved, but insulin secretion is deficient relative to hepatic and peripheral insulin resistance. In particular, the incretin response is deficient (Nauck et al. 1986b), and this finding triggered the introduction of new classes of medications known as GLP-1 receptor agonists (incretin mimetics), and DPP-4 inhibitors (incretin enhancers) (Drucker and Nauck 2006). In type 1 diabetes, insulin secretion is virtually absent, whereas glucagon secretion from the $\alpha$ cell is still preserved, which removes the insulindependent pathways lowering BG levels and, therefore, BG can only go up, leading to hyperglycemia. Thus, insulin replacement is mandatory (Fig. 1B).

A battery of counterregulatory hormones are also at work, including glucagon, epinephrine, cortisol, and growth hormone, which defend, on different time scales, the body from lifethreatening hypoglycemia. Both hypoglycemia counterregulation and insulin control are neuromediated through the brain. However, with intensive insulin treatment, the counterregulatory defenses may fail, risking potentially severe hypoglycemia (White et al. 1983; Cryer and Gerich 1985; Amiel et al. 1988, 1997). Thus, in health, the optimization of blood sugar control is tightly regulated by a hormonal network, and this regulation fails in diabetes at several levels: deficient insulin response from the $\beta$ cell, impaired counterregulation, and inadequate increting effect. External regulation is therefore necessary to alleviate these deficiencies and to maintain strict glycemic control by reducing hyperglycemia without increasing the risk for hypoglycemia. The BG level is both the measurable result of this optimization and the principal feedback signal to the patient, or to technology, for his/her control of diabetes. This understanding of the glucose-insulin control network has been described in formal mathematical terms, which in turn led to modeling, simulation, and, ultimately, to bioelectronic medicine for diabetes (Cobelli et al. 2009).

\section{THE PREVIOUS CENTURY: GLUCOSE CONTROL, MONITORING, AND RISK ANALYSIS}

\section{Intravenous Glucose Control}

Forty-two years after the discovery of insulin, an insulin pump delivering insulin and glucagon (to counteract hypoglycemia) was designed (Kadish 1964). This marked the beginning of attempts to develop automated closed-loop control of diabetes, which can be traced back to the 1970s when the possibility for external BG regulation was established by studies using intravenous (i.v.) glucose measurement and i.v. infusion of glucose and insulin. Five teams reported i.v. closed-loop control results between 1974 and 1978 (Albisser et al. 1974; Pfeiffer et al. 1974; Kraegen et al. 1977; Mirouze et al. 1977; Shichiri et al. 1978). In 1977, one of these designs resulted in the first commercial devicethe Biostator (Clemens et al. 1977) - a large (refrigerator-sized) device that has been used extensively for glucose-control research (Marliss et al. 1977; Fischer et al. 1978; Santiago et al. 1979). A review of methods for i.v. glucose control can be found in Parker et al. (2001). In 1979, another key element-the minimal model of glucose kinetics-was introduced by Bergman et al. (1979). This and subsequent mathematical models serve as the "brain" behind the majority of control algorithms used in contemporary artificial pancreas (AP) systems. Detailed description of the major early algorithm designs can be found in Clemens (1979), Broekhuyse et al. (1981), and Salzsieder et al. (1985). More work followed, spanning a range of control techniques powered by physiologic modeling and computer simulation (Cobelli and Ruggeri 1983; Sorensen 1985; Fischer et al. 1987; Brunetti et al. 1993; Parker et al. 1999). 


\section{Continuous Subcutaneous Insulin Infusion (CSII)}

The first commercial subcutaneous insulin pump-the auto syringe-was introduced by Dean Kamen in the 1970 s and, by the end of the 1970s, the first trials of CSII were reported in the United Kingdom (Pickup et al. 1978) and in the United States (Tamborlane et al. 1979), showing the feasibility of this minimally invasive mode of insulin replacement. The next logical step was automated insulin delivery controlled by a mathematical algorithm-a method that became known as closed-loop control, or the AP. Between 1980 and 2000, the insulin pumps became smaller and portable, whereas the models of the glucose-insulin system became larger and more elaborate, allowing first computer simulation and then automated model-predictive glucose control of diabetes. Figure 2 presents the timeline of these developments.

\section{Glucose Monitoring and Risk Analysis}

In 1969, the first portable BG meter-the Ames reflectance meter-was manufactured. This device set the beginning of what is now known as episodic self-monitoring of blood glucose (SMBG) - the first home-based tool providing data for the day-to-day optimization of diabetes treatment. Various metrics quantifying glycemic variability based on SMBG data were introduced, including but not limited to standard deviation (SD) and coefficient of variation $(\mathrm{CV})$, and diabetes-specific metrics, such as the $M$-value based on a logarithmic transformation of the BG deviation from a preset value (Schlichtkrull et al. 1965); the mean amplitude of glycemic excursions (MAGE) (Service et al. 1970); the Lability Index (Ryan et al. 2004); and the mean absolute glucose (MAG) change (Hermanides et al. 2010). However, the BG measurement scale is quite asymmetric: the hypoglycemic range (below $70 \mathrm{mg} / \mathrm{dL}$ ) is much narrower numerically than the hyperglycemic range $(\mathrm{BG}>180 \mathrm{mg} / \mathrm{dL})$. This asymmetry creates a number of computational problems and challenges. For example, a BG excursion from
180 to $240 \mathrm{mg} / \mathrm{dL}$ is much larger numerically than a BG excursion from 70 to $50 \mathrm{mg} / \mathrm{dL}$, yet the latter carries a much greater risk to the patient. In 1997-1998, the first elements of the risk analysis of BG data were introduced (Kovatchev et al. 1997, 1998), which resolved the asymmetry of the BG scale by a nonlinear transformation that maps the entire $B G$ range (20 to $600 \mathrm{mg} / \mathrm{dL}$ or 1.1 to $33.3 \mathrm{mmol} / \mathrm{L}$ ) to a symmetric interval. The BG value of $112.5 \mathrm{mg} / \mathrm{dL}(6.25 \mathrm{mmol} / \mathrm{L})$ is mapped to zero, corresponding to zero risk for hypo- or hyperglycemia (it should be noted that this is not a normoglycemic or fasting value, which in health would be $<100 \mathrm{mg} / \mathrm{dL}$; it is zero-risk value pertinent to diabetes). The analytical form of this transformation is $f(B G)=\gamma \cdot\left[\ln (B G)^{\alpha}-\beta\right]$, where the parameters are estimated as $\alpha=1.084, \beta=5.381$, and $\gamma=$ 1.509 , if $\mathrm{BG}$ is measured in $\mathrm{mg} / \mathrm{dL}$ and $\alpha=$ $1.026, \beta=1.861$, and $\gamma=1.794$, if BG is measured in $\mathrm{mmol} / \mathrm{L}$. The scale transformation has been introduced in 1997 and its analytical form and parameters have since remained unchanged (Kovatchev et al. 1997; Kovatchev 2017). After fixing the parameters of $f(\mathrm{BG})$, the quadratic function $r(\mathrm{BG})=10 \cdot f(\mathrm{BG})^{2}$ is used to define the $\mathrm{BG}$ risk space. The function $r(\mathrm{BG})$ ranges from 0 to 100 . Its minimum value is 0 and is achieved at $B G=112.5 \mathrm{mg} / \mathrm{dL}$, whereas its maximum is reached at the extreme ends of the BG scale, $20 \mathrm{mg} / \mathrm{dL}$ and $600 \mathrm{mg} / \mathrm{dL}$. Thus, $r(\mathrm{BG})$ can be interpreted as a measure of the risk associated with a certain BG level. The left branch of this parabola identifies the risk of hypoglycemia, whereas the right branch identifies the risk of hyperglycemia (Fig. 3A) (Kovatchev et al. 1998).

The conversion of the BG data into risk values has profound implications not only for the interpretation of the $\mathrm{BG}$ signal, but for control design as well because similar emphasis is placed on the hypoglycemic and hyperglycemic ranges, whereas the normal BG range (70$180 \mathrm{mg} / \mathrm{dL}$ ) is given less weight. Thus, variability contained within normal range carries less risk than excursions outside of this range, whereas excursions into extreme hypo- and hyperglycemia get progressively increasing risk values, which can be used as a cost function 
B. Kovatchev
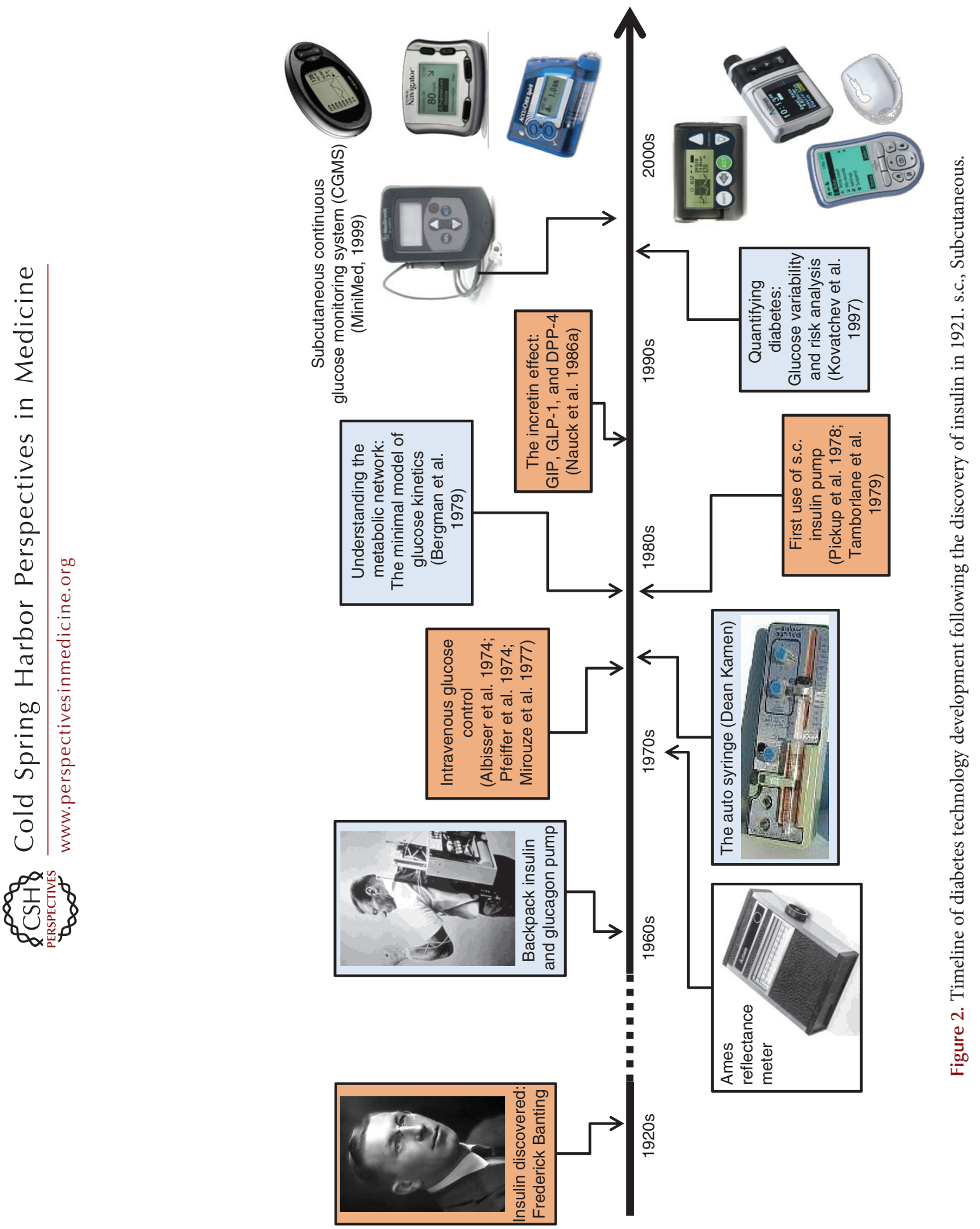
A

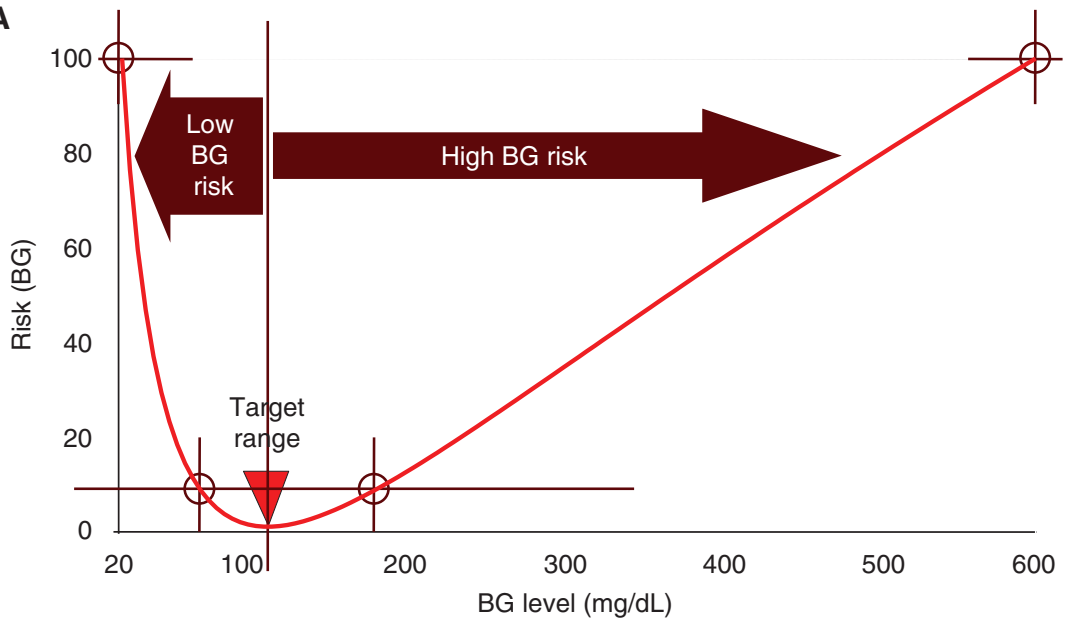

B

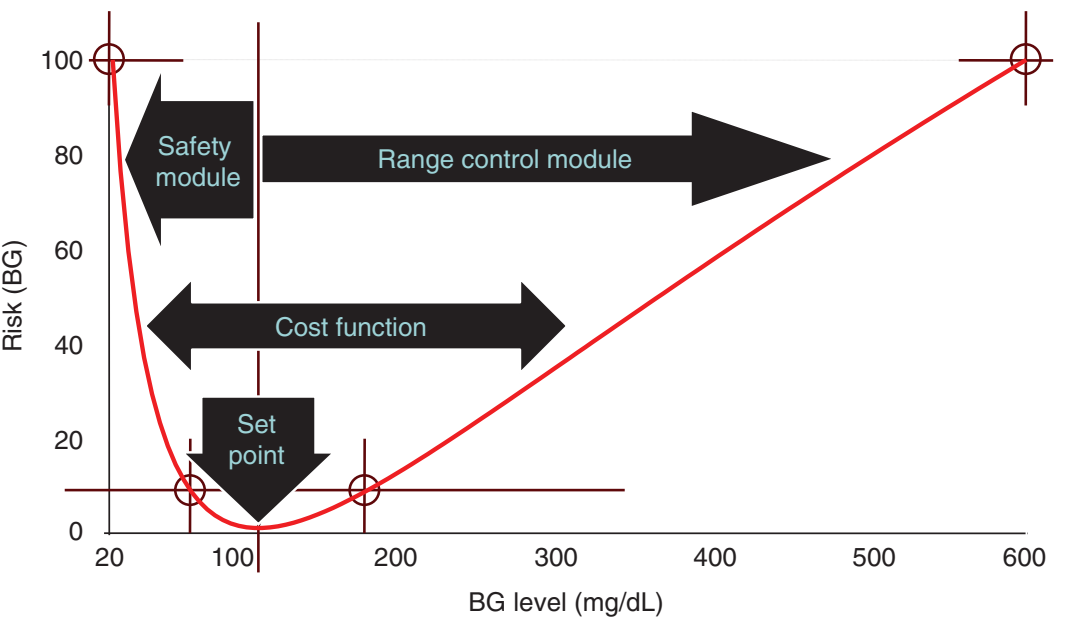

Figure 3. Risks of hypoglycemia and hyperglycemia. The blood glucose (BG) risk function $(A)$ increases steeply when BG levels descend into the hypoglycemic range, and more gradually with the onset of hyperglycemia. Control modules used by artificial pancreas algorithms $(B)$ employ the risk function as a cost function defining algorithm action. The set point of the controller is a zero-risk value and the algorithm aggressiveness is determined by the steepness of the cost function.

by diabetes control algorithms. For example, a modular AP algorithm is based on this risk analysis approach (Patek et al. 2012). As shown in Figure 3B, the set point of the algorithm is at $\mathrm{BG}=112.5 \mathrm{mg} / \mathrm{dL}$, that is, the algorithm targets zero risk. A dedicated safety module preventing hypoglycemia uses the left branch of the risk function to weight risk as BG descends into hypoglycemia, and tailors the algorithm response accordingly. Similarly, a range control module corrects hyperglycemia using the right branch of the risk function.

\section{THE 2000s: CONTINUOUS GLUCOSE MONITORING AND THE ARTIFICIAL PANCREAS}

The final critical technological leap enabling minimally invasive closed-loop control was made at the turn of the 21 st century with the introduction of continuous glucose monitoring (CGM) (Bode 2000; Mastrototaro 2000; Feldman et al. 2003) - an event that started the ongoing quest for a wearable AP. Since the advent of CGM technology, significant progress was 
B. Kovatchev

made toward versatile and reliable CGM devices that not only monitor the entire course of BG day and night, but also provide feedback to the patient, such as alarms when BG reaches preset low or high levels. A number of studies have documented the benefits of CGM (Deiss et al. 2006; Garg et al. 2006; Kovatchev and Clarke 2007; The Juvenile Diabetes Research Foundation Continuous Glucose Monitoring Study Group 2008) and charted guidelines for its clinical use and its future as a precursor to closedloop control (Klonoff 2005, 2007; Hovorka 2006). The next logical step-prevention of hypoglycemia via automated shutoff of the insulin pump when CGM readings cross a predetermined low glucose threshold-was undertaken (Buckingham et al. 2009).

Attempts to fully automate glucose control in diabetes using subcutaneous CGM and subcutaneous insulin pump (i.e., CSII) linked via a closed-loop control algorithm began with the early work of Hovorka et al. (2004) and Steil et al. (2006), and with the launch of the Juvenile Diabetes Research Foundation (JDRF) Artificial Pancreas Consortium, which in 2006 sponsored several centers in the United States and Europe to carry out closed-loop control research. In 2009, the Journal of the American Medical Association (JAMA) wrote: "Artificial pancreas may soon be a reality" (Friedrich 2009). In May 2012, a Diabetes Outlook was published in Nature that highlighted the AP (Dolgin 2012), and 18 months later Science featured the same topic (Clery 2014). Increasing academic and industrial effort was focused on the development of control algorithms, ranging from relatively straightforward proportional-integralderivative (PID) controllers (Steil et al. 2006) to fuzzy-logic (Atlas et al. 2010) and model-predictive algorithms (Hovorka et al. 2004), to dualhormone control that added glucagon to combat hypoglycemia (El-Khatib et al. 2010). In 2008, the National Institutes of Health launched an AP initiative and in 2010 the European AP@Home Consortium was established. A roadmap toward a viable AP was accepted, which included several sequential steps, beginning with automated mitigation of hypoglycemia and progressing through control-to-range and control-to-target toward fully automated, possibly multihormonal AP (Kowalski 2009). By 2010, the AP became a global research topic engaging physicians and engineers in an unprecedented collaboration. In 2014, JAMA revisited the AP and suggested: "Fully automated artificial pancreas finally within reach" (Hampton 2014). Key milestones of this development are described in several reviews (Cobelli et al. 2011; Kovatchev 2011; Renard et al. 2013a,b).

\section{Inpatient AP Studies}

During 2008-2012, promising results were reported by several groups (Weinzimer et al. 2008; Bruttomesso et al. 2009; Clarke et al. 2009; ElKhatib et al. 2010; Hovorka et al. 2010, 2011; Renard et al. 2010; Zisser et al. 2011, 2014; Breton et al. 2012; Russell et al. 2012; Luijf et al. 2013; Sherr et al. 2013). Most of these studies pointed out the superiority of closed-loop control over CSII therapy in terms of (1) increased time within target range (typically 70-180 mg/ $\mathrm{dL}),(2)$ reduced incidence of hypoglycemia, and (3) better overnight control. Inpatient studies linked AP to reduction of hypoglycemia following exercise (Breton et al. 2012; Sherr et al. 2013; Zisser et al. 2014) and an auxiliary heart rate signal was shown to contribute to better exercise control (Breton et al. 2014). An algorithm mimicking $\beta$-cell physiology was embedded in a low-power microchip (Reddy et al. 2014) and a controller running on a smartphone was tested in the hospital (O'Grady et al. 2012). A direct comparison between single- versus dual-hormone AP found "little evidence of glucagon benefits in reducing the number of hypoglycemic events requiring treatment" (Haidar et al. 2015) - an important finding that helped settle the debate about whether dual-hormone AP using glucagon is justified, given the added complexity, possible risks, and expense.

\section{AP System Integration}

Low glucose suspend (LGS), which is now commercially available and is already a part of the clinical practice, is considered a precursor to AP because of the automated data transfer from 
CGM to the insulin pump-a system integration that is a critical step in AP development. The ASPIRE trial showed a $38 \%$ reduction in nocturnal hypoglycemia compared to CGM alone without increasing HbAlc (Bergenstal et al. 2013); a subsequent study achieved similar results (Ly et al. 2013). Predictive LGS algorithms were introduced (Beck et al. 2014), which brought this type of system to a higher level of computational sophistication. However, LGS systems were still binary on-off insulin "switches"; they lacked the defining property of a closed-loop algorithm-feedback estimation of the patient state using CGM and insulin delivery data to determine the degree or insulin modulation in real time.

\section{Outpatient (But Not Portable) AP}

The first steps toward outpatient AP were taken by a laptop-based system installed at the bedside of children at a diabetes camp (Phillip et al. 2013), and then taken to patients' homes (Nimri et al. 2013). Similarly, another bedside AP trial deployed small personal computers at patients' homes, and confirmed their feasibility outside of the hospital (Hovorka et al. 2014). The progress of the outpatient AP was presented in a symposium, "Advances in Artificial Pancreas Development," which contained an editorial (Cefalu and Tamborlane 2014) and seven papers on topics ranging from physiology and engineering (Kudva et al. 2014; Schiavon et al. 2014) to reports on the feasibility of AP in type 2 diabetes (Kumareswaran et al. 2014), overnight and 24/7 outpatient AP with a portable system (Del Favero et al. 2014). Subsequent studies firmly took AP to the outpatient setting (Leelarathna et al. 2014; Russell et al. 2014; Thabit et al. 2014).

\section{Wearable Artificial Pancreas}

In the Nature (Dolgin 2012) and Science (Clery 2014) reviews cited above, a common photo appeared of a smartphone presenting a dual traffic-light display-the face of the first portable AP platform-the Diabetes Assistant (DiAs) developed at the University of Virginia (UVA) in
2011. DiAs was built using an Android smartphone as a computational hub and included a graphical user interface (GUI) designed for the patient (Keith-Hynes et al. 2013) and a webbased remote monitoring system (Place et al. 2013). The defining characteristic of DiAs was its capability to switch between different modes of operation, depending on patient preference and signal availability. For example, if the CGM signal was not available or if the patient does not wear a sensor for a certain period of time, DiAs could switch into "pump mode," running this patient's normal basal/bolus insulin routine and adding extended GUI and remote monitoring. Similarly, if the pump is not available, DiAs could switch to "sensor mode," running trends, alerts, and cloud services. Figure 3 shows the DiAs AP system configuration used in several trials and based on a Dexcom G4 sensor and Roche insulin pump (Fig. 4).

Thus, by design, DiAs was a platform for AP technology deployment-it was not a singlefunction device providing either a fixed closedloop operation, or nothing. DiAs was used in 20 clinical trials, by over 300 patients at clinical centers in the United States (Virginia, California, Minnesota, and New York), as well as in France, Italy, Holland, and Israel. Following initial 2-day pilot-feasibility trials (Cobelli et al. 2012), in 2012-2013, two international multisite studies were completed, which confirmed the feasibility of DiAs and its efficacy to reduce hypoglycemia in the outpatient setting (Kovatchev et al. 2013, 2014). Three summer camp trials of remote monitoring (DeSalvo et al. 2014), overnight AP (Ly et al. 2014), and AP during the day (Chernavvsky et al. 2016), confirmed the efficacy of DiAs in children with type 1 diabetes. With several completed multicenter trials, evening/ overnight closed-loop control is now considered an established and very effective use of portable bioelectronic devices for the control of diabetes (Brown et al. 2015; Del Favero et al. 2015). At the 2015 Advanced Technologies and Treatments for Diabetes Conference in Paris, a special session was dedicated to the recent DiAs studies and a meta-analysis was presented showing significant overall improvement in glycemic control (Renard et al. 2015). 
B. Kovatchev
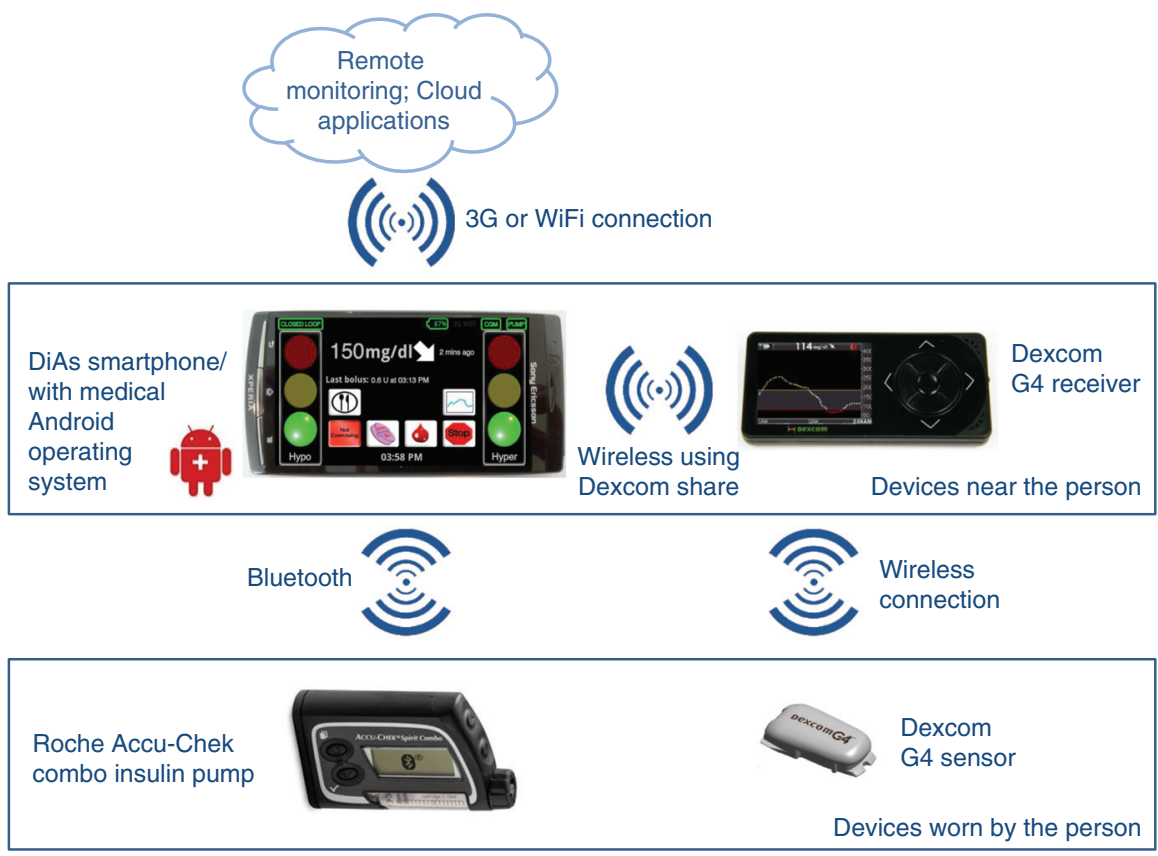

Figure 4. The Diabetes Assistant (DiAs), which became the first portable artificial pancreas (AP). This configuration has been used in several closed-loop control studies: a smartphone using a modified Android operating system, locked to meet medical device requirements, runs the control algorithm, the graphical user interface, and the wireless communications with a continuous glucose monitor (Dexcom G4), an insulin pump (Roche AccuChek), and with a remote server (through WiFi or cellular network) that provides real-time monitoring capabilities, analytics, and database support.

The progress of the AP was presented in a symposium published by Diabetes Care in July 2016 (Kovatchev et al. 2016), which was exclusively dedicated to outpatient closed-loop control studies done with portable AP systems, including trials at patient's homes lasting a month or more (Anderson et al. 2016; Renard et al. 2016; Tauschmann et al. 2016) and studies in young children (Del Favero et al. 2016). In the past 2 years:

1. A pivotal trial of the first commercial hybrid system was completed-the Medtronic 670G, which automatically modulates basal rate but does not automate insulin boluses (Bergenstal et al. 2016).

2. A 6-month pilot-feasibility study of longterm closed-loop control was reported showing improvements in glycemic control and reduction of hypoglycemia with long-term AP use (Kovatchev et al. 2017).
3. Long-term (up to 10 months) studies were initiated using a new commercially developed version of the DiAs system-InControl AP developed by TypeZero Technologies, which runs on Android smartphones and connects wirelessly to a CGM sensor and an insulin pump (Fig. 4).

4. The National Institutes of Health invested over $\$ 35$ million in four pivotal trials of closed-loop control technologies intended to bring these systems to market-a press release (which in particular presented a photo of InControl AP) can be found at www.nih.gov/news-events/news-releases/ four-pivotal-nih-funded-artificial-pancreasresearch-efforts-begin.

5. The first AP Ski Camp and was successfully completed, indicating that the use of closedloop control in the conditions of winter sports ( 5 hours of skiing per day for 5 days) 


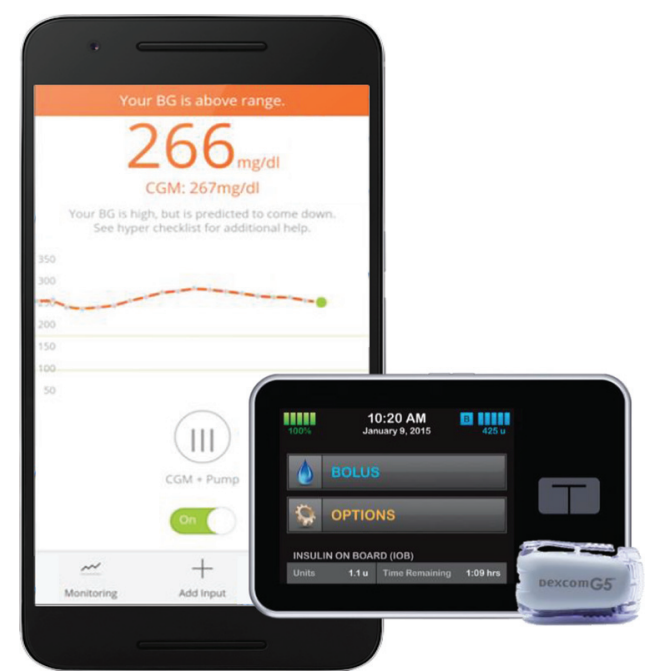

Figure 5. InControl artificial pancreas (AP) is a contemporary mobile artificial pancreas system developed by Type Zero Technologies under a license from the University of Virginia, which is now in use in several long-term clinical trials.

is safe and effective for children and adolescents with type 1 diabetes (Fig. 5) (Breton et al. 2017).

\section{CONCLUSION}

Classic large-scale studies have shown that intensive treatment to maintain optimal average glycemia (as measured by hemoglobin Alc) markedly reduces the chronic complications in both type 1 and type 2 diabetes. External insulin replacement through multiple daily injections (MDIs) or CSII using insulin pumps is mandatory in type 1 diabetes. However, MDI and CSII are not nearly as efficient as the endogenous insulin secretion; thus, acute events do occur, exposing patients to life-threatening severe hypoglycemia or diabetic ketoacidosis. Imperfect intensive insulin treatment may also reduce the warning symptoms and hormonal defenses against hypoglycemia leading to defective counterregulation and hypoglycemia unawareness. As a result, the clinical optimization problem of diabetes was formulated as a "trade-off between glycemic control and iatrogenic hypo- glycemia" (Cryer 2014) and was formalized by risk analysis of BG data.

Arguably, diabetes is one of the best quantified human conditions. A century of diabetes technology development began with the discovery of insulin in 1921, and progressed to contemporary self-monitoring, CGM, minimally invasive subcutaneous insulin delivery, and closed-loop AP devices powered by sophisticated mathematical models of the human metabolic system. AP technology is indeed within reach and is the ultimate bioelectronic medicine approach to improve glucose control in diabetes. Lessons learned in the past 10 years of intense interdisciplinary AP research are listed below.

\section{Abandon Animal Trials}

The 2008, the Food and Drug Administration acceptance of the UVA/University of Padova computer simulator as a substitute for animal trials in the design and safety of preclinical testing of AP controllers opened the field for rapid and cost-effective in silico experiments (Kovatchev et al. 2009a). Since then, virtually no animal experiments have been conducted for the purpose of designing AP algorithms. Virtual environments will allow thorough testing of myriad control cycles in extreme physiological situations, or during low-probability system failures, that cannot be reproduced in real life (Viceconti et al. 2017).

\section{Keep the AP System Modular}

Modular architecture allows AP systems to be assembled from independent (but compatible) modules, each performing a specific function (e.g., prevention of hypoglycemia, postmeal insulin corrections, fine tuning of basal rate, or administration of ancillary compounds such as amylin or glucagon [Kovatchev et al. 2009b]). Modularity is essential for the "graceful degradation" of the system in the event of component failure-the network permits critical functions to be redundant, residing in more than one module, and redirected to avoid system meltdown (Patek et al. 2012). 
B. Kovatchev

\section{Whenever Possible, Use Consumer Electronics}

Traditionally, it is assumed that the AP control system would reside in a patient's insulin pump, which is the case with most commercial developments. An alternative solution was suggested by DiAs, which was based on appropriately configured consumer electronic devices (smartphone). This approach offered advantages to the initial research phase of AP development, and is potentially viable for commercial systems as well.

In conclusion, 2017 became the year of transition of the AP from research topic to clinical practice (Kovatchev 2018). To be ultimately established and accepted as a viable treatment of diabetes, AP systems need to prove their safety and efficacy in large-scale clinical trials with outcomes tied to the key components of glycemic control in diabetes-hemoglobin A1c and risk for hypoglycemia. These validations are ongoing now, and we can be optimistic that the closed-loop AP will indeed become the digitalage treatment of diabetes in the near future.

\section{COMPETING INTEREST STATEMENT}

Patents and patent applications related to diabetes technology are managed by the University of Virginia Licensing and Ventures group. Research support is managed by the University of Virginia from Dexcom, Roche Diagnostics, Tandem Diabetes Care; Speaking Engagement/ Advisory panel/Consultant: Dexcom, Sanofi Aventis; Co-founded and shareholder, TypeZero Technologies.

\section{ACKNOWLEDGMENTS}

The University of Virginia Precision Individualized Medicine for Diabetes (PrIMeD) Project supported the writing of this review.

\section{REFERENCES}

Albisser AM, Leibel BS, Ewart TG, Davidovac Z, Botz CK, Zingg W. 1974. An artificial endocrine pancreas. Diabetes 23: 389-396.
American Diabetes Association. 2004. Diagnosis and classification of diabetes mellitus. Diabetes Care 27: s5-s10.

American Diabetes Association. 2013. Economic costs of diabetes in the U.S. in 2012. Diabetes Care 36: 1033-1046.

Amiel SA, Sherwin RS, Simonson DC, Tamborlane WV. 1988. Effect of intensive insulin therapy on glycemic thresholds for counterregulatory hormone release. Diabetes 37: 901-907.

Amiel SA, Tamborlane WV, Simonson DC, Sherwin RS. 1997. Defective glucose counterregulation after strict glycemic control of insulin-dependent diabetes mellitus. N Engl J Med 316: 1376-1383.

Anderson SM, Raghinaru D, Pinsker JE, Boscari F, Renard E, Buckingham BA, Nimri R, Doyle FJ III, Brown SA, KeithHynes P, et al. 2016. Multinational home use of closedloop control is safe and effective. Diabetes Care 39: 11431150.

Atlas E, Nimri R, Miller S, Grunberg EA, Phillip M. 2010. MD-logic artificial pancreas system: A pilot study in adults with type 1 diabetes. Diabetes Care 33: 1072-1076.

Beck RW, Raghinaru D, Wadwa RP, Chase HP, Maahs DM, Buckingham BA; for the In Home Closed Loop Study Group. 2014. Frequency of morning ketosis after overnight insulin suspension using an automated nocturnal predictive low glucose suspend system. Diabetes Care 37: 1224-1229.

Bergenstal RM, Klonoff DC, Garg SK, Bode BW, Meredith M, Slover RH, Ahmann AJ, Welsh JB, Lee SW, Kaufman FR, et al. 2013. Threshold-based insulin-pump interruption for reduction of hypoglycemia. $N$ Engl J Med 369: 224-232.

Bergenstal RM, Garg S, Weinzimer SA, Buckingham BA, Bode BW, Tamborlane WV, Kaufman FR. 2016. Safety of a hybrid closed-loop insulin delivery system in patients with type 1 diabetes. JAMA 316: 1407-1408.

Bergman RN, Ider YZ, Bowden CR, Cobelli C. 1979. Quantitative estimation of insulin sensitivity. Am J Physiol 236: E667-E677.

Bode BW. 2000. Clinical utility of the continuous glucose monitoring system. Diabetes Technol Ther 2: S35-S42.

Breton MD, Farret A, Bruttomesso D, Anderson SM, Magni L, Patek S, Dalla Man C, Place J, Demartini S, Del Favero S, et al. 2012. Fully-integrated artificial pancreas in type 1 diabetes: Modular closed-loop glucose control maintains near-normoglycemia. Diabetes 61: 2230-2237.

Breton MD, Brown SA, Karvetski CH, Kollar L, Topchyan KA, Anderson SM, Kovatchev BP. 2014. Adding heart rate signal to a control-to-range artificial pancreas system improves the protection against hypoglycemia during exercise in type 1 diabetes. Diabetes Technol Ther 16: 506-511.

Breton MD, Cherñavvsky DR, Forlenza GP, DeBoer MD, Robic J, Wadwa RP, Messer LH, Kovatchev BP, Maahs DM. 2017. Closed loop control during intense prolonged outdoor exercise in adolescents with type 1 diabetes: The Artificial Pancreas Ski Study. Diabetes Care 40: 1644-1650.

Broekhuyse HM, Nelson JD, Zinman B, Albisser AM. 1981. Comparison of algorithms for the closed-loop control of blood glucose using the artificial $\beta$ cell. IEEE Trans Biomed Eng 28: 678-687. 
Brown SA, Kovatchev BP, Breton MD, Anderson SM, KeithHynes P, Patek SD, Jiang B, Ben Brahim N, Vereshchetin P, Bruttomesso D, et al. 2015. Multinight "bedside" closed-loop control for patients with type 1 diabetes. Diabetes Technol Ther 17: 203-209.

Brunetti P, Cobelli C, Cruciani P, Fabietti PG, Filippucci F, Santeusanio F. 1993. A simulation study on a self-tuning portable controller of blood glucose. Int J Artificial Organs 16: 51-57.

Bruttomesso D, Farret A, Costa S, Marescotti MC, Vettore M, Avogaro A, Tiengo A, Dalla Man C, Place J, Facchinetti A, et al. 2009. Closed-loop artificial pancreas using subcutaneous glucose sensing and insulin delivery, and a model predictive control algorithm: Preliminary studies in Padova and Montpellier. J Diabetes Sci Technol 3: 1014-1021.

Buckingham B, Cobry E, Clinton P, Gage V, Caswell K, Kunselman E, Cameron F, Chase HP. 2009. Preventing hypoglycemia using predictive alarm algorithms and insulin pump suspension. Diabetes Technol Ther 11: 93-97.

Cefalu WT, Tamborlane WV. 2014. The artificial pancreas: Are we there yet? Diabetes Care 37: 1182-1183.

Chernavvsky DR, DeBoer MD, Keith-Hynes P, Mize B, McElwee M, Demartini S, Dunsmore SF, Wakeman C, Kovatchev BP, Breton MD. 2016. Use of an artificial pancreas among adolescents for a missed snack bolus and an underestimated meal bolus. Pediatr Diabetes 17: 28-35.

Clarke WL, Anderson SM, Breton MD, Patek SD, Kashmer L, Kovatchev BP. 2009. Closed-loop artificial pancreas using subcutaneous glucose sensing and insulin delivery and a model predictive control algorithm: The Virginia experience. J Diabetes Sci Technol 3: 1031-1038.

Clemens AH. 1979. Feedback control dynamics for glucose controlled insulin infusion system. Med Prog Technol 6: 91-98.

Clemens AH, Chang PH, Myers RW. 1977. The development of Biostator, a glucose-controlled insulin infusion system (GCIIS). Horm Metab Res 7: 23-33.

Clery D. 2014. A pancreas in a box. Science 343: 133-115.

Cobelli C, Ruggeri A. 1983. Evaluation of portal/peripheral route and of algorithms for insulin delivery in the closedloop control of glucose in diabetes. A modeling study. IEEE Trans Biomed Eng 30: 93-103.

Cobelli C, Dalla Man C, Sparacino G, Magni L, De Nicolao G, Kovatchev BP. 2009. Diabetes: Models, signals, and control. IEEE Rev Biomed Eng 2: 54-96.

Cobelli C, Renard E, Kovatchev BP. 2011. Artificial pancreas: Past, present, future. Diabetes 60: 2672-2682.

Cobelli C, Renard E, Kovatchev BP, Keith-Hynes P, Ben Brahim N, Place J, Del Favero S, Breton MD, Farret A, Bruttomesso D, et al. 2012. Pilot studies of wearable artificial pancreas in type 1 diabetes. Diabetes Care $\mathbf{3 5}$ e65-e67.

Cryer PE. 2014. Glycemic goals in diabetes: Trade-off between glycemic control and iatrogenic hypoglycemia. $\mathrm{Di}$ abetes 63: 2188-2195.

Cryer PE, Gerich JE. 1985. Glucose counterregulation, hypoglycemia, and intensive therapy of diabetes mellitus. N Engl J Med 313: 232-241.

Deiss D, Bolinder J, Riveline J, Battelino T, Bosi E, TubianaRufi N, Kerr D, Phillip M. 2006. Improved glycemic control in poorly controlled patients with type 1 diabetes using real-time continuous glucose monitoring. Diabetes Care 29: 2730-2732.

Del Favero S, Bruttomesso D, Di Palma F, Lanzola G, Visentin R, Filippi A, Scotton R, Toffanin C, Messori M, Scarpellini S, et al. 2014. First use of model predictive control in outpatient wearable artificial pancreas. Diabetes Care 37: 1212-1215.

Del Favero S, Place J, Kropff J, Messori M, Keith-Hynes P, Visentin R, Monaro M, Galasso S, Boscari F, Toffanin C, et al. 2015. Multicenter outpatient dinner/overnight reduction of hypoglycemia and increased time of glucose in target with a wearable artificial pancreas using modular model predictive control in adults with type 1 diabetes. Diabetes Obes Metab 17: 468-476.

Del Favero S, Boscari F, Messori M, Rabbone I, Bonfanti R, Sabbion A, IaFusco D, Schiaffini R, Visentin R, Calore R, et al. 2016. Randomized summer camp crossover trial in 5- to 9-year-old children: Outpatient wearable artificial pancreas is feasible and safe. Diabetes Care 39: 11801185.

DeSalvo D, Keith-Hynes P, Peyser T, Place J, Caswell K, Wilson D, Harris B, Clinton P, Kovatchev BP, Buckingham BA. 2014. Remote glucose monitoring in camp setting reduces the risk of prolonged nocturnal hypoglycemia. Diabetes Technol Ther 16: 1-7.

Dolgin E. 2012. Managed by machine. Nature 485: S6-S8.

Drucker DJ, Nauck MA. 2006. The incretin system: Glucagon-like peptide-1 receptor agonists and dipeptidyl peptidase- 4 inhibitors in type 2 diabetes. Lancet 368 : 1696-1705.

El-Khatib FH, Russell SJ, Nathan DM, Sutherlin RG, Damiano ER. 2010. A bihormonal closed-loop artificial pancreas for type 1 diabetes. Sci Transl Med 2: 27ra27.

Feldman B, Brazg R, Schwartz S, Weinstein R. 2003. A continuous glucose sensor based on wired enzyme technology-Results from a 3-day trial in patients with type 1 diabetes. Diabetes Technol Ther 5: 769-778.

Fischer U, Jutzi E, Freyse EJ, Salzsieder E. 1978. Derivation and experimental proof of a new algorithm for the artificial $\beta$-cell based on the individual analysis of the physiological insulin-glucose relationship. Endokrinologie 71: 65-75.

Fischer U, Schenk W, Salzsieder E, Albrecht G, Abel P, Freyse EJ. 1987. Does physiological blood glucose control require an adaptive strategy? IEEE Trans Biomed Eng 34: 575582.

Friedrich MJ. 2009. Artificial pancreas may soon be a reality. JAMA 301: 1525-1527.

Garg K, Zisser H, Schwartz S, Bailey T, Kaplan R, Ellis S, Jovanovic L. 2006. Improvement in glycemic excursions with a transcutaneous, real-time continuous glucose sensor. Diabetes Care 29: 44-50.

Haidar A, Legault L, Messier V, Mitre TM, Leroux C, Rabasa-Lhoret R. 2015. Comparison of dual-hormone artificial pancreas, single hormone artificial pancreas, and conventional insulin pump therapy for glycaemic control in patients with type 1 diabetes: An open-label randomised controlled crossover trial. Lancet Diabetes Endocrinol 3: 17-26.

Hampton T. 2014. Fully automated artificial pancreas finally within reach. JAMA 311: 2260-2261. 
B. Kovatchev

Hermanides J, Vriesendorp TM, Bosman RJ, Zandstra DF, Hoekstra JB, Devries JH. 2010. Glucose variability is associated with intensive care unit mortality. Crit Care Med 38: 838-842.

Hovorka R. 2006. Continuous glucose monitoring and closed-loop systems. Diabet Med 23: 1-12.

Hovorka R, Chassin LJ, Wilinska ME, Canonico V, Akwi JA, Federici MO, Massi-Benedetti M, Hutzli I, Zaugg C, Kaufmann H, et al. 2004. Closing the loop: The ADICOL experience. Diabetes Technol Ther 6: 307-318.

Hovorka R, Allen JM, Elleri D, Chassin LJ, Harris J, Xing D, Kollman C, Hovorka T, Larsen AMF, Nodale M, et al. 2010. Manual closed-loop insulin delivery in children and adolescents with type 1 diabetes: A phase 2 randomised crossover trial. Lancet 375: 743-751.

Hovorka R, Kumareswaran K, Harris J, Allen JM, Elleri D, Xing D, Kollman C, Nodale M, Murphy HR, Dunger DB, et al. 2011. Overnight closed loop insulin delivery in adults with type 1 diabetes: Crossover randomised controlled studies. BMJ 342: d1855.

Hovorka R, Elleri D, Thabit H, Allen JM, Leelarathna L, ElKhairi R, Kumareswaran K, Caldwell K, Calhoun P, Kollman C, et al. 2014. Overnight closed-loop insulin delivery in young people with type 1 diabetes: A free-living, randomized clinical trial. Diabetes Care 37: 1204-1211.

Kadish AH. 1964. Automation control of blood sugar. A servomechanism for glucose monitoring and control. Am J Med Electron 39: 82-86.

Keith-Hynes P, Guerlain S, Mize LB, Hughes-Karvetski C, Khan M, McElwee-Malloy M, Kovatchev BP. 2013. DiAs user interface: A patient-centric interface for mobile artificial pancreas systems. J Diabetes Sci Technol 7: 14161426.

Klonoff DC. 2005. Continuous glucose monitoring: Roadmap for 21st century diabetes therapy. Diabetes Care 28: 1231-1239.

Klonoff DC. 2007. The artificial pancreas: How sweet engineering will solve bitter problems. J Diabetes Sci Technol 1: $72-81$

Kovatchev BP. 2011. Closed loop control for type 1 diabetes. BMJ 342: 1-2.

Kovatchev BP. 2017. Metrics for glycaemic control: From HbA1c to continuous glucose monitoring. Nat Rev Endocrinol 13: 425-436.

Kovatchev BP. 2018. The artificial pancreas in 2017: The year of transition from research to clinical practice. Nature Reviews Endocrinology 14: 74-76.

Kovatchev BP, Clarke WL. 2007. Continuous glucose monitoring reduces risks for hypo- and hyperglycemia and glucose variability in diabetes. Diabetes 56: 0086OR.

Kovatchev BP, Cox DJ, Gonder-Frederick LA, Clarke WL. 1997. Symmetrization of the blood glucose measurement scale and its applications. Diabetes Care 20: 1655-1658.

Kovatchev BP, Cox DJ, Gonder-Frederick LA, YoungHyman D, Schlundt D, Clarke WL. 1998. Assessment of risk for severe hypoglycemia among adults with IDDM: Validation of the low blood glucose index. Diabetes Care 21: 1870-1875.

Kovatchev BP, Breton MD, Dalla Man C, Cobelli C. 2009a. In silico preclinical trials: A proof of concept in closed-loop control of type 1 diabetes. J Diabetes Sci Technol 3: 44-55.
Kovatchev BP, Patek SD, Dassau E, Doyle FJ III, Magni L, De Nicolao G, Cobelli C. 2009b. Control-to-range for diabetes: Functionality and modular architecture. J Diabetes Sci Technol 3: 1058-1065.

Kovatchev BP, Renard E, Cobelli C, Zisser H, Keith-Hynes P, Anderson SM, Brown SA Chernavvsky DR, Breton MD, Farret A, et al. 2013. Feasibility of outpatient fully integrated closed-loop control: First studies of wearable artificial pancreas. Diabetes Care 36: 1851-1858.

Kovatchev BP, Renard E, Cobelli C, Zisser H, Keith-Hynes P, Anderson SM, Brown SA, Chernavvsky DR, Breton MD, Mize LB, et al. 2014. Safety of outpatient closed-loop control: First randomized crossover trials of a wearable artificial pancreas. Diabetes Care 37: 1789-1796.

Kovatchev BP, Tamborlane WV, Cefalu WT, Cobelli C. 2016. The artificial pancreas in 2016: A digital treatment ecosystem for diabetes. Diabetes Care 39: 1123-1127.

Kovatchev BP, Cheng P, Anderson SM, Pinsker JE, Boscari F, Buckingham BA, Doyle FJ III, Hood KK, Brown SA, Breton MD, et al. 2017. Feasibility of long-term closed-loop control: A multicenter 6-month trial of 24/6 automated insulin delivery. Diabetes Technol Ther 19: 18-24.

Kowalski AJ. 2009. Can we really close the loop and how soon? Accelerating the availability of an artificial pancreas: A roadmap to better diabetes outcomes. Diabetes Technol Ther 11: S113-S119.

Kraegen EW, Campbell LV, Chia YO, Meler H, Lazarus L. 1977. Control of blood glucose in diabetics using an artificial pancreas. Aust N Z J Med 7: 280-286.

Kudva YC, Carter RE, Cobelli C, Basu R, Basu A. 2014 Closed-loop artificial pancreas systems: Physiological input to enhance next-generation devices. Diabetes Care 37: 1184-1190.

Kumareswaran K, Thabit H, Leelarathna L, Caldwell K, Elleri D, Allen JM, Nodale M, Wilinska ME, Evans ML, Hovorka R. 2014. Feasibility of closed-loop insulin delivery in type 2 diabetes: A randomized controlled study. Diabetes Care 37: 1198-1203.

Lachin JM, Genuth S, Nathan DM, Zinman B, Rutledge BN; DCCT/EDIC Research Group. 2008. Effect of glycemic exposure on the risk of microvascular complications in the Diabetes Control and Complications Trial revisited. Diabetes 57: 995-1001.

Leelarathna L, Dellweg S, Mader JK, Allen JM, Benesch C, Doll W, Ellmerer M, Hartnell S, Heinemann L, Kojzar H, et al. 2014. Day and night home closed-loop insulin delivery in adults with type 1 diabetes: Three-center randomized crossover study. Diabetes Care 37: 1931-1937.

Luijf YM, DeVries JH, Zwinderman K, Leelarathna L, Nodale M, Caldwell K, Kumareswaran K, Elleri D, Allen JM, Wilinska ME, et al. 2013. Day and night closed-loop control in adults with type 1 diabetes: A comparison of two closed-loop algorithms driving continuous subcutaneous insulin infusion versus patient self-management. Diabetes Care 36: 3882-3887.

Ly TT, Nicholas JA, Retterath A, Lim EM, Davis EA, Jones TW. 2013. Effect of sensor-augmented insulin pump therapy and automated insulin suspension vs. standard insulin pump therapy on hypoglycemia in patients with type 1 diabetes: A randomized clinical trial. JAMA 310: 1240-1247. 
Ly TT, Breton MD, Keith-Hynes P, De Salvo D, Clinton P, Benassi K, Mize LB, Chernavvsky DR, Place J, Wilson $\mathrm{DM}$, et al. 2014. Overnight glucose control with an automated, unified safety system in children and adolescents with type 1 diabetes at diabetes camp. Diabetes Care 37: 2310-2316.

Marliss EB, Murray FT, Stokes EF, Zinman B, Nakhooda AF, Denoga A, Leibel BS, Albisser AM. 1977. Normalization of glycemia in diabetics during meals with insulin and glucagon delivery by the artificial pancreas. Diabetes 26: 663-672.

Mastrototaro JJ. 2000. The MiniMed continuous glucose monitoring system. Diabetes Technol Ther 2: S-13-S-18.

Mirouze J, Selam JL, Pham TC, Cavadore D. 1977. Evaluation of exogenous insulin homeostasis by the artificial pancreas in insulin-dependent diabetes. Diabetologia 13: $273-278$

Nauck MA, Homberger E, Siegel EG, Allen RC, Eaton RP, Ebert R, Creutzfeldt W. 1986a. Incretin effects of increasing glucose loads in man calculated from venous insulin and C-peptide responses. J Clin Endocrinol Metab 63: 492-498

Nauck M, Stöckmann F, Ebert R, Creutzfeldt W. 1986b. Reduced incretin effect in type 2 (non-insulin-dependent) diabetes. Diabetologia 29: 46-52.

Nimri R, Danne T, Kordonouri O, Atlas E, Bratina N, Biester T, Avbelj M, Miller S, Muller I, Phillip M, et al. 2013. The "glucositter" overnight automated closed loop system for type 1 diabetes: A randomized crossover trial. Pediatr Diabetes 14: 159-167.

O'Grady MJ, Retterath AJ, Keenan DB, Kurtz N, Cantwell M, Spital G, Kremliovsky MN, Roy A, Davis EA, Jones TW et al. 2012. The use of an automated, portable, glucose control system for overnight glucose control in adolescents and young adults with type 1 diabetes. Diabetes Care 35: 2182-2187.

Parker RS, Doyle FJ III, Peppas NA. 1999. A model-based algorithm for blood glucose control in type I diabetic patients. IEEE Trans Biomed Eng 48: 148-157.

Parker RS, Doyle FJ III, Peppas NA. 2001. The intravenous route to blood glucose control. IEEE Eng Med Biol 20: 6573.

Patek SD, Magni L, Dassau E, Karvetski CH, Toffanin C, DeNicolao G, DelFaverok S, Breton M, Dalla Man C, Renard E, et al. 2012. modular closed-loop control of diabetes. Trans Biomed Eng 59: 2986-2999.

Pfeiffer EF, Thum C, Clemens AH. 1974. The artificial $\beta$ cell -A continuous control of blood sugar by external regulation of insulin infusion (glucose controlled insulin infusion system). Horm Metab Res 6: 339-342.

Phillip M, Battelino T, Atlas E, Kordonouri O, Bratina N, Miller S, Biester T, Stefanija MA, Muller I, Nimri R, et al. 2013. Nocturnal glucose control with an artificial pancreas at a diabetes camp. $N$ Engl J Med 368: 824-833.

Pickup JC, Williams G. 2003. Textbook of diabetes 2. Blackwell, Oxford.

Pickup JC, Keen H, Parsons JA, Alberti KG. 1978. Continuous subcutaneous insulin infusion: An approach to achieving normoglycaemia. BMJ 1: 204-207.

Place J, Robert A, Ben Brahim N, Keith-Hynes P, Farret A, Pelletier MJ, Buckingham B, Breton M, Kovatchev BP,
Renard E. 2013. DiAs web monitoring: A real-time remote monitoring system designed for artificial pancreas outpatient trials. J Diabetes Sci Technol 7: 1427-1435.

Reddy M, Herrero P, El Sharkawy M, Pesl P, Jugnee N, Thomson H, Pavitt D, Toumazou C, Johnston D, Georgiou P, et al. 2014. Feasibility study of a bio-inspired artificial pancreas in adults with type 1 diabetes. Diabetes Technol Ther 16: 550-557.

Reichard P, Pihl M. 1994. Mortality and treatment side effects during long-term intensified conventional insulin treatment in the Stockholm Diabetes Intervention Study. Diabetes 43: 313-317.

Renard EM, Farret A, Place J, Cobelli C, Kovatchev BP, Breton MD. 2010. Closed-loop insulin delivery using subcutaneous infusion and glucose sensing, and equipped with a dedicated safety supervision algorithm, improves safety of glucose control in type 1 diabetes. Diabetologia 53: S25.

Renard E, Cobelli C, Kovatchev BP. 2013a. Closed loop developments to improve glucose control at home. Diabetes Res Clin Pract 102: 79-85.

Renard E, Cobelli C, Zisser H, Kovatchev BP. 2013b. Artificial pancreas goes outpatient: A new diabetes ecosystem. J Diabetes Sci Technol 7: 1411-1415.

Renard E, Keith-Hynes P, Brown S, De Vries JH, Cobelli C, Buckingham B, Anderson SM, Kovatchev BP. 2015. Twelve years of collaborative transatlantic research on artificial pancreas; first presentations of the 2014 studies. In Special session at Advanced Technologies and Treatments for Diabetes (ATTD). Paris, France.

Renard E, Farret A, Kropff J, Bruttomesso D, Messori M, Place J, Visentin R, Calore R, Toffanin C, Di Palma F, et al. 2016. Day and night closed loop glucose control in patients with type 1 diabetes under free-living conditions: Comparison of a single-arm, 1-month experience to results of a previously reported feasibility study of evening and night at home. Diabetes Care 39: 1151-1160.

Russell SJ, El-Khatib FH, Nathan DM, Magyar KL, Jiang J, Damiano ER. 2012. Blood glucose control in type 1 diabetes with a bihormonal bionic endocrine pancreas. Diabetes Care 33: 2148-2155.

Russell SJ, El-Khatib FH, Sinha M, Magyar KL, McKeon K, Goergen LG, Balliro C, Hillard MA, Nathan DM, Damiano ER. 2014. Outpatient glycemic control with a bionic pancreas in type 1 diabetes. $N$ Engl J Med 371: 313-325.

Ryan EA, Shandro T, Green K, Paty BW, Senior PA, Bigam D, Shapiro AM, Vantyghem MC. 2004. Assessment of the severity of hypoglycemia and glycemic lability in type 1 diabetic subjects undergoing islet transplantation. Diabetes 53: 955-962.

Salzsieder E, Albrecht G, Fischer U, Freyse EJ. 1985. Kinetic modeling of the gluco-regulatory system to improve insulin therapy. IEEE Trans Biomed Eng 32: 846-855.

Santiago JV, Clemens AH, Clarke WL, Kipnis DM. 1979. Closed-loop and open-loop devices for blood glucose control in normal and diabetic subjects. Diabetes 28: 71-84.

Schiavon M, Dalla Man C, Kudva YC, Basu A, Cobelli C. 2014. Quantitative estimation of insulin sensitivity in type 1 diabetic subjects wearing a sensor-augmented insulin pump. Diabetes Care 37: 1216-1223. 
B. Kovatchev

Schlichtkrull J, Munck O, Jersild M. 1965. The $M$-value, an index of blood-sugar control in diabetics. Acta Med Scand 177: 95-102.

Service FJ, Molnar GD, Rosevear JW, Ackerman E, Gatewood LC, Taylor WF. 1970. Mean amplitude of glycemic excursions, a measure of diabetic instability. Diabetes 19: 644-655.

Sherr JL, Cengiz E, Palerm CC, Clark B, Kurtz N, Roy A, Carria L, Cantwell M, Tamborlane WV, Weinzimer SA. 2013. Reduced hypoglycemia and increased time in target using closed-loop insulin delivery during nights with or without antecedent afternoon exercise in type 1 diabetes. Diabetes Care 36: 2909-2914.

Shichiri M, Kawamori R, Yamasaki Y, Inoue M, Shigeta Y, Abe H. 1978. Computer algorithm for the artificial pancreatic $\beta$ cell. Artif Organs 2: 247-250.

Sorensen JT. 1985. "A physiologic model of glucose metabolism in man and its use to design and assess improved insulin therapies for diabetes." PhD thesis, Massachusetts Institute of Technology, Cambridge, MA.

Steil GM, Rebrin K, Darwin C, Hariri F, Saad MF. 2006 Feasibility of automating insulin delivery for the treatment of type 1 diabetes. Diabetes 55: 3344-3350.

Tamborlane WV, Sherwin RC, Genel M, Felig P. 1979. Reduction to normal of plasma glucose in juvenile diabetes by subcutaneous administration of insulin with a portable infusion pump. N Engl J Med 300: 573-578.

Tauschmann M, Allen JM, Wilinska ME, Thabit H, Stewart Z, Cheng P, Kollman C, Acerini CL, Dunger DB, Hovorka R. 2016. Day-and-night hybrid closed-loop insulin delivery in adolescents with type 1 diabetes: A free-living, randomized clinical trial. Diabetes Care 39: 1168-1174.

Thabit H, Lubina-Solomon A, Stadler M, Leelarathna L, Walkinshaw E, Pernet A, Allen JM, Iqbal A, Choudhary P, Kumareswaran K, et al. 2014. Home use of closed-loop insulin delivery for overnight glucose control in adults with type 1 diabetes: A 4-week, multicentre, randomised crossover study. Lancet Diabetes Endocrinol 2: 701-709.

The Diabetes Control and Complications Trial Research Group. 1993. The effect of intensive treatment of diabetes on the development and progression of long-term complications of insulin-dependent diabetes mellitus. NEnglJ Med 329: 978-986.
The Diabetes Control and Complications Trial Research Group. 1995. The relationship of glycemic exposure (HbAlc) to the risk of development and progression of retinopathy in the Diabetes Control and Complications Trial. Diabetes 44: 968-983.

The Juvenile Diabetes Research Foundation Continuous Glucose Monitoring Study Group. 2008. Continuous glucose monitoring and intensive treatment of type 1 diabetes. N Engl J Med 359: 1464-1476.

UK Prospective Diabetes Study Group (UKPDS). 1998 Intensive blood-glucose control with sulphonylureas or insulin compared with conventional treatment and risk of complications in patients with type 2 diabetes. Lancet 352: $837-853$.

Viceconti M, Cobelli C, Haddad T, Himes A, Kovatchev BP, Palmer M. 2017. In silico assessment of biomedical products: The conundrum of rare but not so rare events in two case studies. Proc Inst Mech Eng H 231: 455-466.

Weinzimer SA, Steil GM, Swan KL, Dziura J, Kurtz N, Tamborlane WV. 2008. Fully automated closed-loop insulin delivery versus semi-automated hybrid control in pediatric patients with type 1 diabetes using an artificial pancreas. Diabetes Care 31: 934-939.

White NH, Skor DA, Cryer PE, Levandoski L, Santiago JV. 1983. Identification of type 1 diabetic patients at increased risk for hypoglycemia during intensive therapy. $N$ Engl J Med 308: 485-491.

Wilson RH, Foster DW, Kronenberg HN, Larsen PR. 2011. Williams textbook of endocrinology, 12th ed. Elsevier, Philadelphia.

Zisser H, Dassau E, Bevier W, Harvey R, Percival MW, Grosman B, Seborg D, Jovanovič L, Doyle FJ III. 2011. Initial evaluation of a fully automated artificial pancreas. Diabetes 60: A41.

Zisser H, Renard E, Kovatchev BP, Cobelli C, Avogaro A, Nimri E, Magni L, Buckingham B, Chase HP, Doyle FJ III, et al. 2014. Multicenter closed-loop insulin delivery study points to challenges for keeping blood glucose in a safe range by a control algorithm in adults and adolescents with type 1 diabetes from various sites. Diabetes Technol Ther 16: 613-622. 


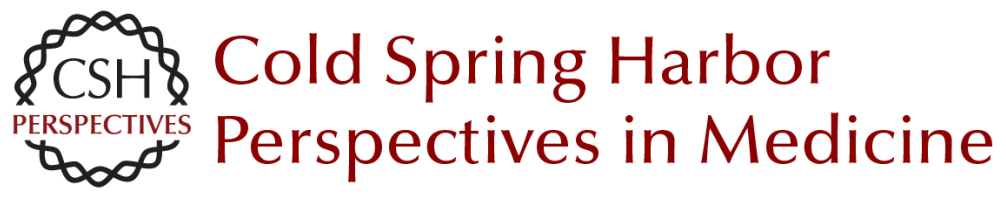

\section{Diabetes Technology: Monitoring, Analytics, and Optimal Control}

Boris Kovatchev

Cold Spring Harb Perspect Med 2019; doi: 10.1101/cshperspect.a034389 originally published online August 20, 2018

\section{Subject Collection Bioelectronic Medicine}

Neural Control of Inflammation: Bioelectronic Medicine in Treatment of Chronic Inflammatory

Disease

Michael Eberhardson, Laura Tarnawski, Monica

Centa, et al.

Noninvasive Neuromodulation of Peripheral Nerve

Pathways Using Ultrasound and Its Current

Therapeutic Implications

Christopher Puleo and Victoria Cotero

Enteric Neuromodulation for the Gut and Beyond

Yogi A. Patel and Pankaj J. Pasricha

\section{Optogenetic Control of the Peripheral Nervous} System

Rui B. Chang

Closed-Loop Neuromodulation in Physiological and Translational Research Stavros Zanos

Electrical Impedance Methods in Neuromuscular Assessment: An Overview

Seward B. Rutkove and Benjamin Sanchez

Optogenetic Medicine: Synthetic Therapeutic

Solutions Precision-Guided by Light Haifeng Ye and Martin Fussenegger

Technobiology's Enabler: The Magnetoelectric Nanoparticle

Sakhrat Khizroev
Bioelectronic Medicine: From Preclinical Studies on the Inflammatory Reflex to New Approaches in Disease Diagnosis and Treatment

Valentin A. Pavlov, Sangeeta S. Chavan and Kevin J. Tracey

Vagus Nerve Stimulation and the Cardiovascular System

Michael J. Capilupi, Samantha M. Kerath and

Lance B. Becker

Harnessing the Inflammatory Reflex for the

Treatment of Inflammation-Mediated Diseases

Yaakov A. Levine, Michael Faltys and David

Chernoff

Recording and Decoding of Vagal Neural Signals

Related to Changes in Physiological Parameters

and Biomarkers of Disease

Theodoros P. Zanos

Restoring Movement in Paralysis with a

Bioelectronic Neural Bypass Approach: Current

State and Future Directions

Chad E. Bouton

Bioelectronic Medicine--Ethical Concerns Samuel Packer, Nicholas Mercado and Anita Haridat

Use of Bioelectronics in the Gastrointestinal Tract Larry Miller, Aydin Farajidavar and Anil Vegesna

Vagus Nerve Stimulation at the Interface of BrainGut Interactions

Bruno Bonaz, Valérie Sinniger and Sonia Pellissier

For additional articles in this collection, see http://perspectivesinmedicine.cshlp.org/cgi/collection/ 